\title{
Motility and chemotaxis of Escherichia coli in medium with attractant and repellent
}

\author{
Reyes Alvin T1,2* Ambita Dave1, Batalon Jamie Louise ${ }^{1}$, Aba Berna Lou ${ }^{1}$, Cortes Angelbert ${ }^{1}$, \\ Macabecha Cherray Gabrielle ${ }^{1}$ and Montecillo Andrew ${ }^{1}$ \\ ${ }^{1}$ University of the Philippines Los Baños, College Laguna Philippines; \\ ${ }^{2}$ College of Fisheries-Freshwater Aquaculture Center, Central Luzon State University, Science City of Muñoz, Nueva Ecija, Philippines
}

\begin{abstract}
This study was conducted in order to satisfy the following objectives: (1) To compare the migration bands of Escherichia coli, Bacillus megaterium and Staphylococcus aureus in Sugar, Indole and Motility (SIM) medium + chemotaxis medium (CM), SIM + attractant (glucose), SIM + repellent (alcohol) and SIM only; (2) To observe and compare the swimming behaviour of E. coli under the microscope in the presence of attractant and repellent; and (3) To compare chemotaxis of E. coli in the presence of attractant and repellent by capillary assay. Motility bands were observed in tubes with SIM + CM, SIM + attractant, SIM + repellent and SIM only that were inoculated with E. coli and B. megaterium. However, the motility band in SIM + repellent travelled less far as compared to SIM + CM and SIM + attractant. No motility ba nds were observed in tubes inoculated with $S$. aureus. Highest number of colonies (CFU/mL) were observed in capillary tubes dipped in attractant (3.7 x $10^{8}$ ), followed by CM $\left(5.2 \times 10^{7}\right)$ and least in repellent $\left(7.6 \times 10^{6}\right)$. Analysis of data showed that log CFU/mL in capillary tubes dipped in attractant $(8.55 \pm 0.14)$ was significantly higher as compared to capillary tubes dipped in CM (7.64 \pm 0.29$)$ and repellent $(6.87 \pm 0.14)$.
\end{abstract}

Keywords: Escherichia coli, motility, chemotaxis, attractant, repellent

Article Info: Received 14 July 2019; $\quad$ Review Completed 24 August 2019; $\quad$ Accepted 30 August 2019; Available online 15 Sep 2019

Cite this article as:

Reyes AT, Ambita D, Batalon JL, Aba BL, Cortes A, Macabecha CG, Montecillo A, Motility and chemotaxis of Escherichia coli in medium with attractant and repellent, Journal of Drug Delivery and Therapeutics. 2019; 9(5):15-18

http://dx.doi.org/10.22270/jddt.v9i5.3532

*Address for Correspondence:

Reyes Alvin, College of Fisheries-Freshwater Aquaculture Center, Central Luzon State University, Science City of Muñoz, Nueva Ecija, Philippines

\section{INTRODUCTION}

By the end of the 19th century, the motor responses of bacteria had been thoroughly characterized by numerous investigators including Wilhelm Pfeffer, a great German physiologist ${ }^{1}$. The research of Pfeffer established that bacteria move in response to changes in temperature (thermotaxis), light (phototaxis), salinity (osmotaxis) and oxygen (aerotaxis), and to specific metabolites and other signalling molecules (chemotaxis). It was not until the end of the $20^{\text {th }}$ century, however, that the molecular mechanisms that underlie bacterial sensory-motor regulation had been established ${ }^{1}$.

Bacterial chemotaxis is defined as a physiological response to environmental stimuli in which the organisms move toward a favourable medium or swim away from a hazardous medium ${ }^{2,3}$. Chemotactic bacteria use complex intracellular response systems as they are too small to sense changes in their biochemical environment relative to the length of their cell. Escherichia coli is the most widely studied chemotactic bacterium, along with Bacillus subtilis, Pseudomonas aeruginosa and Rhodobacter sphaeroides ${ }^{4}$.

Chemotactic bacteria rely upon three physiological components in order to detect and respond to their environment. According to Stock et al. (2000) and Wolanin et al. (2002), motile prokaryotes use a two-component signal transduction system with conserved components to regulate motor activity5,6. In general, a two-component system includes a histidine protein kinase (HPK) that catalyzes the transfer of phosphoryl groups from ATP to one of its own histidine residues and a response regulator that catalyzes transfer of phosphoryl groups from the HPK-histidine to an aspartate residue on the response regulator ${ }^{7}$.

\section{Objectives of the Study}

The objectives of this study include: (1) To compare the migration bands of E. coli, B. megaterium and Staphylococcus aureus in Sugar, Indole and Motility (SIM) medium + chemotaxis medium (CM), SIM + attractant, SIM + repellent and SIM only; (2) To observe and compare the swimming 
behaviour of $E$. coli under the microscope in the presence of attractant and repellent; and (3) To compare chemotaxis of E. coli in the presence of attractant and repellent by capillary assay.

\section{MATERIALS AND METHODS}

\section{Demonstration of Bacterial Migration Bands}

E. coli, B. megaterium and S. aureus (negative control, nonmotile) were separately grown in Luria Bertani (LB) agar slant for 18-24 hours. SIM medium was prepared in tubes and autoclaved at $121{ }^{\circ} \mathrm{C}$ at 15 psi for 15 minutes. Chemotaxis medium (CM) which is composed of $10^{-3} \mathrm{M}$ EDTA, $10^{-3}$ mannitol, $10^{-2} \mathrm{MgCl}$ and $10^{-2} \mathrm{~K}_{2} \mathrm{HPO}_{4}-\mathrm{KH}_{2} \mathrm{PO}_{4}$ buffer ( $\mathrm{pH} \mathrm{7)}$ was also prepared. Afterwards, CM, glucose (attractant) and absolute ethanol (repellent) were filter sterilized. The following tubes were prepared: (1) SIM only, (2) SIM + CM, (3) SIM + glucose as attractant and (4) SIM + ethanol as repellent. The CM, glucose and ethanol were added in SIM before it solidifies. The final concentration of glucose and ethanol in tubes with SIM was $1 \mathrm{M}$.

The 18-24 hours bacterial cultures were separately resuspended in $1 \mathrm{~mL} 0.0037$ EDTA solution. Afterwards, 20 $\mu \mathrm{L}$ of resuspended E. coli was pipetted out and dropped into the surface of the prepared tubes with SIM + CM, SIM + glucose and SIM + ethanol. Meanwhile, stab inoculation was done in tube with SIM medium only. Each tube was replicated twice. The same procedure was done using $B$. megaterium and $S$. aureus. The tubes were then allowed to stand for 5-6 hours and migration bands were observed as indicators of motility.

\section{Demonstration of Chemotaxis by Microscopic Assay}

Five millilitre of filter sterilized CM was added into 18-24 hours culture of $E$. coli to resuspend the cells. Filter sterilized glucose and ethanol were set aside. Clean depression slides and cover slips were prepared through flame sterilization. The hanging drop technique was employed to observe the motility of the bacterium. Approximately $9 \mu \mathrm{l}$ of resuspended E. coli cells were placed on a cover slip; the cover slip and drop were then inverted over the well of a depression slide. This procedure was repeated with addition of glucose or ethanol in the resuspended E. coli cells. The motility of $E$. coli was observed under the oil immersion objective of light microscope. The motility was also videodocumented.

\section{Demonstration of Chemotaxis by Capillary Assay}

Freshly grown $E$. coli was resuspended in CM for 30 minutes. Afterwards, $200 \mu \mathrm{l}$ of the cell suspension was transferred into three sterile Eppendorf tubes. Meanwhile, $200 \mu \mathrm{l}$ of $\mathrm{CM}$, $1 \mathrm{M}$ glucose and $1 \mathrm{M}$ absolute ethanol were separately placed in sterile Eppendorf tubes that contain two $1 \mu \mathrm{l}$ capillary tubes. After 10 minutes, the capillary tubes were dipped into Eppendorf tubes with $200 \mu \mathrm{l}$ cell suspension for 45 minutes to allow the entry of cells. After 45 minutes, the capillary tubes were removed from the cell suspension and its exteriors were washed with distilled water. The content of the capillary tube was resuspended in $100 \mu \mathrm{l}$ diluent. The cells were serially diluted, and $100 \mu \mathrm{l}$ of $10^{-2} 10^{-3}$ and $10^{-4}$ dilutions for $\mathrm{CM}, 10^{-3}, 10^{-4}$ and $10^{-5}$ dilutions for glucose, and $10^{-1} 10^{-2}$ and $10^{-3}$ dilutions for alcohol were spread plated on prepared LB plates. The plates were incubated at room temperature and the number of colonies was counted after 24 hours.

\section{RESULTS AND DISCUSSION}

In E. coli and B. megaterium, motility bands were observed in SIM + CM, SIM + attractant, SIM + repellent and SIM only. However, the motility band in SIM + repellent travelled less far as compared to SIM + CM and SIM + attractant. No motility bands were observed in S. aureus inoculated in SIM with CM, attractant or repellent, and SIM only (Figure 1). $S$. aureus served as negative control since this is a non-motile bacterium.

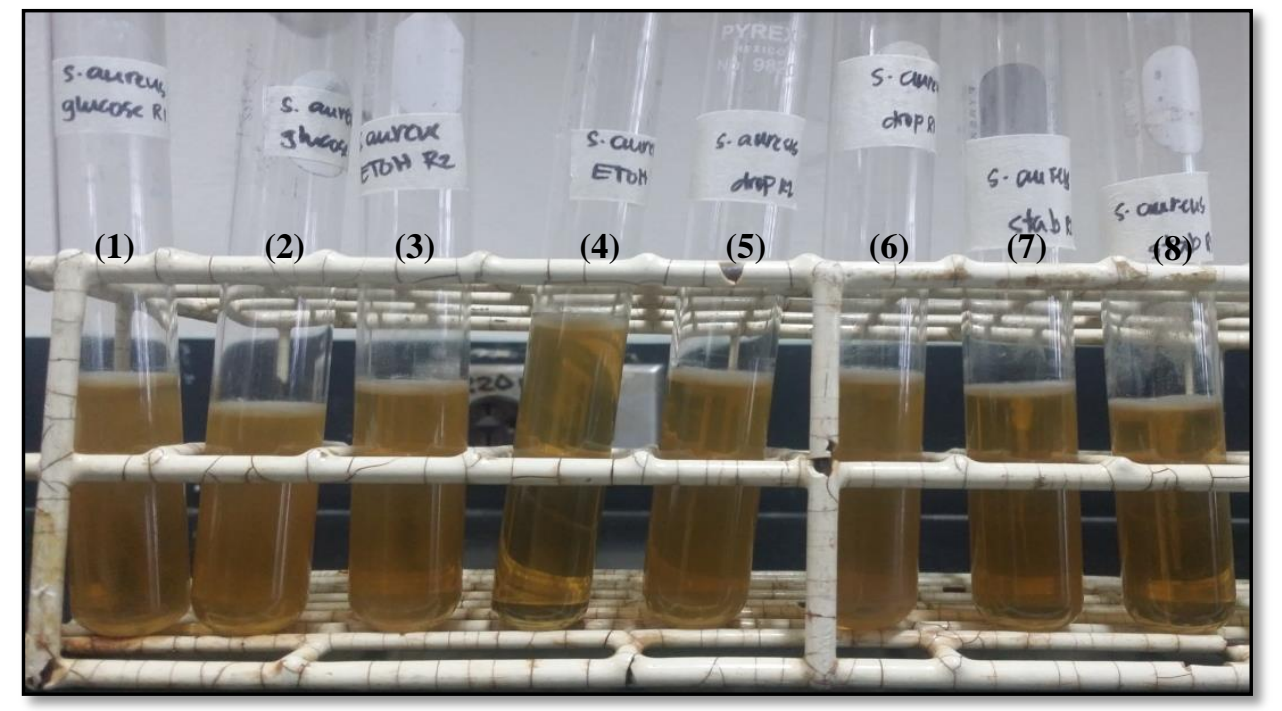

Figure 1A: S. aureus inoculated in SIM + glucose (tubes 1 and 2), SIM + alcohol (tubes 3 and 4), SIM + CM (tubes 5 and 6 ) and SIM only (tubes 7 and 8). No motility bands were observed. 


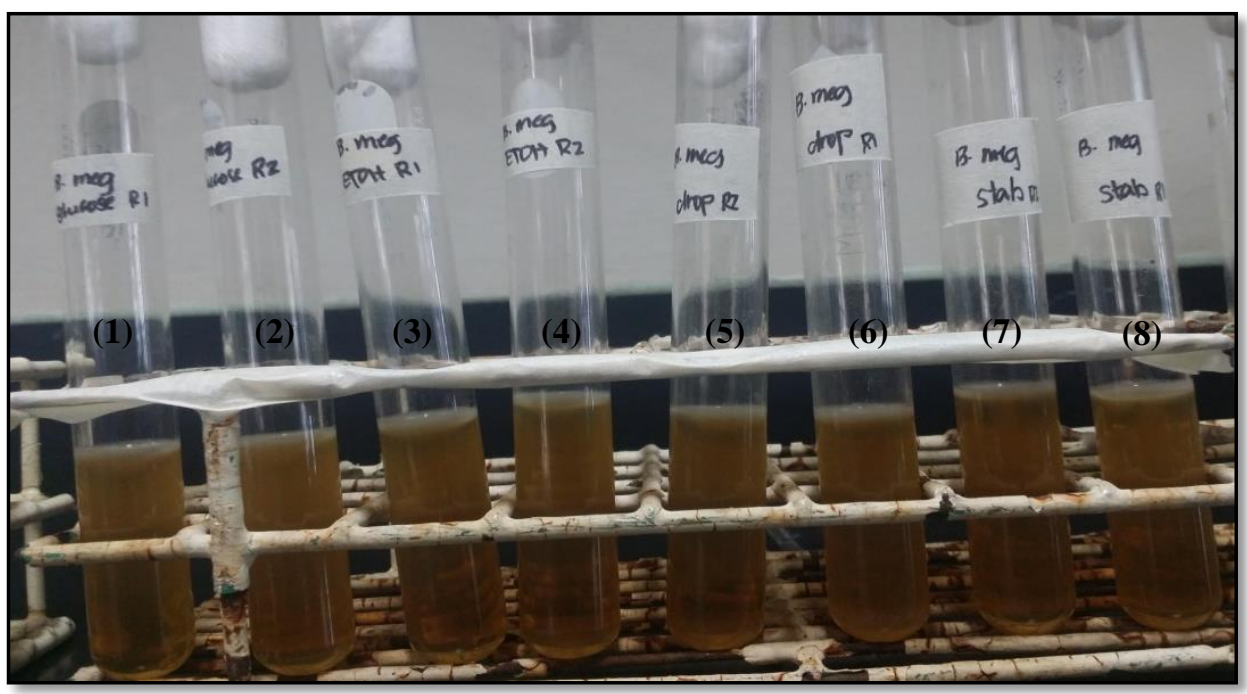

Figure 1B: B. megaterium inoculated in SIM + glucose (tubes 1 and 2), SIM + alcohol (tubes 3 and 4), SIM + CM (tubes 5 and 6 ) and SIM only (tubes 7 and 8). Motility bands were observed in all tubes.

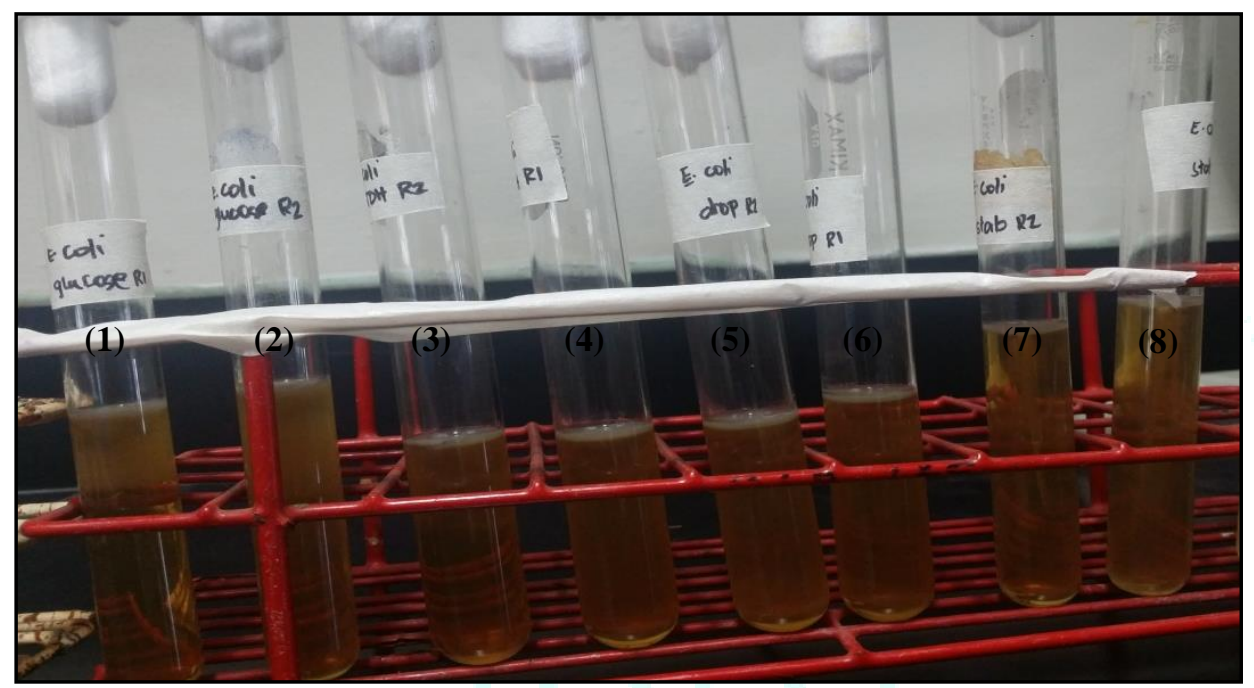

Figure 1C: E. coli inoculated in SIM + glucose (tubes 1 and 2), SIM + alcohol (tubes 3 and 4), SIM + CM (tubes 5 and 6 ) and SIM only (tubes 7 and 8). Motility bands were observed in all tubes.

Highest count (CFU/mL) was observed in capillary tubes dipped in attractant $\left(3.7 \times 10^{8}\right)$, followed by $\mathrm{CM}\left(5.2 \times 10^{7}\right)$ and least in repellent $\left(7.6 \times 10^{6}\right)$ (Table 1). The colony counts were linearized (log) first before subjecting it to statistical analysis (One-way ANOVA, Tukey's test). Analysis of data showed that $\log \mathrm{CFU} / \mathrm{mL}$ in capillary tubes dipped in attractant (8.55 \pm 0.14$)$ was significantly higher as compared to capillary tubes dipped in CM $(7.64 \pm 0.29)$ and repellent $(6.87 \pm 0.14)(\mathrm{p}<0.05)($ Figure 2$)$.

Table 1. Number of $E$. coli colonies ( $\mathrm{CFU} / \mathrm{mL}$ ) in capillary tubes dipped in $\mathrm{CM}$, attractant and repellent.

\begin{tabular}{|c|c|c|c|c|}
\hline & Dilution & No. of Colonies & $\mathrm{CFU} / \mathrm{mL}$ & $\log C F U / m L$ \\
\hline \multirow{4}{*}{$\begin{array}{c}\text { Chemotaxis } \\
\text { Medium }\end{array}$} & \multirow{4}{*}{$10^{-4}$} & 260 & $2.6 \times 10^{7}$ & 7.415 \\
\hline & & 923 & $9.2 \times 10^{7}$ & 7.964 \\
\hline & & 237 & $2.4 \times 10^{7}$ & 7.380 \\
\hline & & 645 & $6.5 \times 10^{7}$ & 7.813 \\
\hline \multirow{4}{*}{ Attractant } & \multirow{4}{*}{$10^{-5}$} & 416 & $4.2 \times 10^{8}$ & 8.623 \\
\hline & & 522 & $5.2 \times 10^{8}$ & 8.716 \\
\hline & & 247 & $2.5 \times 10^{8}$ & 8.400 \\
\hline & & 303 & $3.0 \times 10^{8}$ & 8.477 \\
\hline \multirow{4}{*}{ Repellent } & \multirow{4}{*}{$10^{-3}$} & 457 & $4.6 \times 10^{6}$ & 6.663 \\
\hline & & 834 & $8.3 \times 10^{6}$ & 6.919 \\
\hline & & 820 & $8.2 \times 10^{6}$ & 6.914 \\
\hline & & 934 & $9.3 \times 10^{6}$ & 6.968 \\
\hline
\end{tabular}




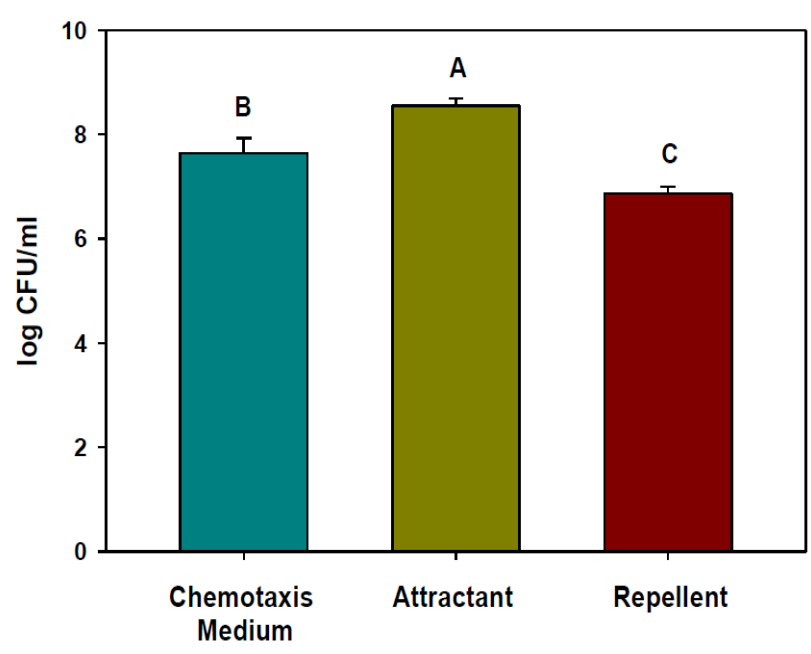

Figure 2. Linearized E. coli count (log CFU/mL) in capillary tubes dipped in $\mathrm{CM}$, attractant and repellent (different letter showed significant difference at $\mathrm{p}<0.05)$.

Most bacteria such as E. coli bias their swimming motion towards specific attractants and away from repellents ${ }^{2,8}$. It was extensively studied that E. coli cells swim towards amino acids (serine and aspartic acid), sugars (maltose, ribose, galactose, glucose), dipeptides, pyrimidines and electron acceptors (oxygen, nitrate, fumarate). According to Adler et al. (1973), the most effective attractants are those that have thresholds near $10^{-5} \mathrm{M}$ or below. Conversely, E. coli swims away from potentially noxious chemicals such as alcohols and fatty acids ${ }^{9}$.

According to Berg and Brown (1972), the motion of E. coli resembles a random walk having periods of smooth swimming that is interrupted by brief tumbles that could change the swimming direction ${ }^{10}$. As observed under microscope, the tendency of $E$. coli to tumble was enhanced when the bacterium perceives conditions to be worsening such as the addition of repellent, which in our case was absolute alcohol. Conversely, tumbling was suppressed and cells keep running when they detect that conditions are improving, in our case, when sugar was being added. Thus, when a bacterium runs up a gradient of attractants or down a gradient of repellents it tends to continue on course.

In addition, increasing the concentration of attractant and decreasing the concentration of repellent will result to decrease frequency of tumbling. Meanwhile, decreasing concentration of attractant and increasing concentration of repellent will result to increase frequency of tumbling 1 .

E. coli response to attractant and repellent is mediated by protein network ${ }^{5,8}$. Using data from behavioural, genetic, biochemical and structural studies, the signal transduction pathway mediating $E$. coli chemotaxis has been extensively characterized ${ }^{11,12}$. E. coli can sense a variety of amino acids, sugars and dipeptides, as well as $\mathrm{pH}$, temperature and redox state. Information about the chemical environment is transduced into the cells by chemoreceptors (e.g. aspartate receptor Tar), which span the membrane. The chemoreceptors form complexes inside the cells with the kinase CheA and CheW. CheA phosphorylates itself and then transfers phosphoryl groups to a diffusible messenger protein, the CheY. A tumble is induced when the phosphorylated CheY interacts with the flagellar motors ${ }^{13,14}$. The rate of CheY dephosphorylation is greatly enhanced by CheZ. Tumbling is reduced when attractants bind to the receptors, thus, decreasing the rate of CheY phosphorylation. Adaptation is provided by changes in the level of methylation of the chemoreceptors; methylation increases the rate of CheY phosphorylation 13,14. Enzymes such as CheR and CheB are responsible in adding and removing methyl groups. In order to adapt to an attractant, methylation of the receptors must rise to overcome the suppression of receptor activity caused by the attractant binding. CheA enhances the demethylating activity of $\mathrm{CheB}$ by phosphorylating CheB on its amino-terminal domain ${ }^{13,14}$.

\section{CONCLUSION}

The tendency of $E$. coli to tumble was enhanced when the bacterium perceives conditions to be worsening, such as the addition of repellent, which in our case was absolute alcohol. Conversely, tumbling was suppressed and cells keep running when they detect that conditions are improving, in our case, when sugar was being added. E. coli response to attractant and repellent is mediated by protein network.

\section{REFERENCES}

1. Adler J, 1975, Chemotaxis in bacteria, Annual Review of Biochemistry, 1975; 44:341-356.

2. Stock JB, Surette MG, Chemotaxis. In: Escherichia coli and Salmonella. cellular and molecular biology (F.C. Neidhardt, R. Curtis III, J.L. Ingraham, E.C.C. Lin, K.B. Low, B. Magsanik, W.S. Reznikoff, M. Riley, M. Schaechter and H.E. Umbarger, eds.), ASM Press, Washington, DC, 1996; 1:1103-1129.

3. Bischoff DS, Ordal GW, Bacillus subtilis chemotaxis: A deviation from the Escherichia coli paradigm, Molecular Microbiology, 1992; 6:23-28.

4. Eisenbach M, Lengeler JW, Varon M, Gutnick D, Meili R, Firtel RA, Segall JE, Omann GM, Tamada A, Murakami F, Chemotaxis, London: Imperial College Press, 2004.

5. Stock AM, Robinson VL, Goudreau PN, Two-component signal transduction, Annual Review of Biochemistry, 200; 69:183215.

6. Wolanin PM, Thomason PA, Stock JB, Histidine protein kinases: Key signal transducers outside the animal kingdom, Genome Biolology 3: Reviews, 2002; 3013.1-3013.8.

7. Borkovich KA, Kaplan N, Hess JF, Simon MI, Transmembrane signal transduction in bacterial chemotaxis involves liganddependent activation of phosphate group transfer, Proceedings of the National Academy of Sciences of the United States of America, 1989; 86:1208-1212.

8. Falke JJ, Bass RB, Butler SL, Chervitz SA, Danielson MA, The two component signalling pathway of bacterial chemotaxis: A molecular view of signal transduction by receptors, kinases, and adaptation enzymes, Annual Review of Cell and Developmental Biology, 1997; 13:457-512.

9. Adler J, Hazelbauer GL, Dahl MM, Chemotaxis toward sugar in Escherichia coli. Journal of Bacteriology, 19873; 115(3):82447.

10. Berg HC, Brown DA, Chemotaxis in Escherichia coli analysed by three dimensional tracking, Nature, 1972; 239:500-504.

11. Bren A, Eisenbach M, How signals are heard during bacterial chemotaxis: Protein-protein interactions in sensory signal propagation, Journal of Bacteriology, 2000; 182:6865-6873.

12. Bourret RB, Stock AM, Molecular information processing: Lessons from bacterial chemotaxis, Journal of Biological Chemistry, 202; 277:9625-962.

13. Stewart RC, Russel CB, Roth AF, Dahlquist FW, Interaction of CheB with chemotaxis signal transduction components in Escherichia coli: Modulation of the methylesterase activity and effects on cell swimming behavior. Cold Spring Harbor Symposia on Quantitative Biology, 1988; 27-40.

14. Lupas A, Stock JB, Phosphorylation of an N-terminus regulatory domain activates the $\mathrm{CheB}$ methylesterase in bacterial chemotaxis, Journal of Biological Chemistry, 1989; 264:17337-17342. 